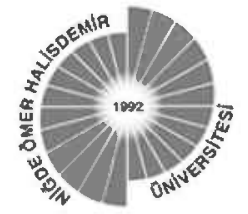

Araştırma Makalesi

Research Article
Ömer Halisdemir Üniversitesi İktisadi ve İdari Bilimler Fakültesi Dergisi

Yul: 2019 Cilt-Sayl: 12 (2) ss: 316-327

Academic Review of Economics and Administrative Sciences

Year: 2019 Vol-Issue: 12 (2) pp: 316-327

http://dergipark.gov.tr/ohuiibf/

\title{
ELEKTRIK TÜKETIMI, KARBON EMISYONU VE EKONOMIK BÜYÜME ÍLIŞKİSi (1995-2014)
}

\author{
Serdar ÖZTÜRK $K^{1}$ \\ Tuba KÜSMEZ ${ }^{2}$
}

\section{$\ddot{o}_{z e t}$}

Bu çalışmada elektrik tüketimi, karbon emisyonu ve ekonomik büyüme arasındaki iliş̧i incelenmiştir. Çalışmada 1995-2014 yll aralığında karbon emisyonu dünya ortalamasının üzerinde olan ülkeler kullanılarak Panel Vektör Otoregresif (VAR) tekniğiyle analiz yapllmıştr. Panel VAR analizinden elde edilen sonuçlara göre karbon emisyonu ve enerji tüketimi arasinda negatif ve anlamli bir ilişki olduğu bulunmuştur. Ayrica çallşmada yaptlan nedensellik testinden elde edilen sonuçlartna göre ise elektrik tüketiminden CO2 emisyonlartna doğru tek yönlü nedensellik ilişkisi bulunmuştur. Bu sonuçlara göre seçilen ülkelerde elektrik tüketiminde yaşanacak bir gelişmenin karbon emisyonların etkileyebileceği yorumu yapılabilmektedir. Ele alınan ülkeler emisyonları düşürmeye yönelik olan, ekonomik büyümelerini olumsuz etkilemeyecek şekilde yapllacak yatırımları desteklemeli ve enerji verimliliğinin sağlanmast için politikalar geliştirmelidirler.

Anahtar Kelimeler $\quad$ : Karbon emisyonu, elektrik tüketimi, büyüme, panel veri analizi.

Jel Siniflandinlmast $\quad: Q 43, Q 40, Q 53, C 33$.

\footnotetext{
${ }^{1}$ Prof. Dr., Nevşehir Hacı Bektaş Veli Üniversitesi, İ.İ.B.F., İktisat Bölümü, serdarozturk@nevsehir.edu.tr, ORCID: 0000-0003-06500244

${ }^{2}$ Doktora Öğrencisi, Nevşehir Hacı Bektaş Veli Üniversitesi, SBE, tubahanifi@hotmail.com, ORCID: 0000-0002-7642-3769
} 


\title{
Electricity Consumption, Co2 Emission AND ECONOMIC GROWTH (1995-2014)
}

\begin{abstract}
This study, the relationship between electricity consumption, carbon emission and economic growth is investigated. In the study, by using countries with carbon emissions above the world average in the period of 1995-2014, Panel Vector Autoregressive (VAR) technique is used. According to the results obtained from the panel VAR analysis, it was found that there was a negative and significant relationship between carbon emission and energy consumption. In addition, according to the results obtained from the causality test conducted in the study, one-way causality relationship is found between electricity consumption and CO2 emissions. According to these results, it can be interpreted that an improvement in electricity consumption in selected countries may affect carbon emissions. The countries involved should support investments in order to reduce emissions, do not adversely affect their economic growth and develop policies to ensure energy efficiency.
\end{abstract}

Key Words

Jel Classification

\begin{abstract}
: Carbon emission, electricity consumption, growth, panel data analysis.
\end{abstract}
: Q43, Q40, Q53, C33.

\section{GİRIŞ}

Artan sanayileşme seviyeleri, değişen yaşam tarzları, hızla artan nüfus ve artan elektrik tüketimi dünyada küresel ısınma tehdidini ortaya çıkarmıştır. Enerji arzının talebe uydurulma çabası, küresel ısınma ile ilgili endişeler ekonomik büyüme, elektrik tüketimi ve karbon emisyonları (CO2) arasındaki ilişkinin incelenmesi bakımından dikkat çeken konular arasında yer almıştır (Cowan vd., 2014). Gelişmekte olan ülkeler ve pazarlar ekonomik gelişmeyi hızlandırmaktadır. Hızlı nüfus artışı ve kentleşme dünyada enerji tüketiminin artmasının nedenleri arasında yer almaktadır. Bununla birlikte artan enerji tüketimi özellikle fosil yakıtların kullanılmasıyla çevreye olumsuz etkiler bırakmaktadır (Zhang vd. 2017). Farklı ekonomik faaliyetlerde enerji olarak kullanılan elektrik, ekonomik büyümenin temel faktörleri arasında yer almaktadır. Elektrik tüketimi, $\mathrm{CO} 2$ emisyonu ve ekonomik büyüme kavramları arasındaki ilişkiyi anlamak, hükümetlerin enerji politikalarını belirlemeleri açısından önem arz etmektedir (Payne, 2010).

Bu çalışmada 1995-2014 yıl aralığında elektrik tüketimi, karbon emisyonu ve ekonomik büyüme arasındaki ilișkiyi incelenecektir. Bu ilișkinin incelenmesi için karbon emisyonu dünya ortalamasının üzerinde olan ülkeler kullanılarak Panel Vektör Otoregresif (VAR) tekniğiyle analiz yapılacaktır. Çalışmanın dünya CO2 emisyonu ortalamasının üzerinde olan verilerine ulaşılabilen 44 ülke için konunun incelenmesi bakımından literatürde yer alan boşluğu dolduracağı düşünülmektedir. $\mathrm{Bu}$ nedenle bu çalışmanın amacı elektrik tüketimi ve ekonomik büyüme değişkenlerinin seçilmiş ülkelerde CO2 emisyonuna yol açıp açmadığını incelemektir.

Çalışmanın planı şu şekilde düzenlenmiştir: Bölüm 1'de elektrik tüketimi, ekonomik büyüme ve karbon emisyonlarının kavramsal çerçevesi oluşturularak teorik bilgilere yer verilmektedir. Bölüm 2, elektrik tüketimi, ekonomik büyüme ve karbon emisyonu ile ilgili literatür incelemesi yapılmaktadır. Bölüm 3, çalışmada kullanılan veri seti gösterilmekte, kullanılacak analiz yöntemi ve elde edilen çıkarımlar açıklanarak, makalenin ampirik bulguları ve sonuçları yorumlanmaktadır. 


\section{TEORIK INCELEME}

Son yıllarda iklim değişikliği en önemli çevresel sorunlardan biri haline gelmiștir. Gelişmiş ülkelerin, emisyonların büyük bir kısmından sorumlu olduğu fakat son yıllarda gelişmekte olan ülkelerdeki emisyonların daha yüksek olduğu bilinmektedir. Örneğin Çin karbon emisyonu dünya ortalamasından yüksek olan ülkeler arasında yer almaktadır (Dünya Bankası, 2018). Fosil yakıtlardan kaynaklanan emisyonların çevresel etkileri nedeniyle yenilenebilir enerji kaynakları $\mathrm{CO} 2$ emisyonlarını azaltmak ve iklim değişikliğini kontrol altına almak için kullanılan ikame bir enerji kaynağı olmuştur (Lorente vd. 2018). Ülkelerin küresel ısınma, sera gazlarının azaltılması ve iklim değişikliği konusunda mücadelelerini sağlayan, uluslar arası geçerli olan çerçeve Kyoto Protokol'üdür. Sera gazlarının azaltılmasına yönelik düzenlemeler içeren Kyoto Protokolü, 169 ülkenin katılımıyla 11 Aralık 1997'de imzalanmıștır. Şubat 2005'te yürürlüğe giren Protokol'ün çevre dostu teknoloji transferlerini teşvik etme, emisyon verilerini düzenleme, bu verilerin kalitesini yükseltme ve hatta bazı ülkelerde belirli emisyon hedefleri koymak gibi maddeleri bulunmaktadır. Günümüzde Kyoto Protokol'üne 191 ülke ve Avrupa Birliği taraftır. Protokol'ün amacı ülkelerin atmosfere yaydıklanı sera gazı miktarlarını 1990 yılındaki düzeylere düşürmektir. Protokole imza atmayan ülkeler arasında $\mathrm{ABD}$ ve Avustralya yer almaktadır. Çin ve Hindistan gibi bazı ülkeler ise anlaşmaya imza atmalarına rağmen protokolde bulunan "küresel sera gazı emisyonlarının gelişmiş ülkeler tarafindan gerçekleştirildiği, gelişmekte olan ülkelerin kişis başı gaz emisyonlarının halen düşük olduğu, gelişmekte olan ülkelerin küresel emisyonlarının ihtiyaçlarına göre artacağı" hükmüne göre emisyonlarında herhangi bir azaltmaya gitmemektedirler (Özmen, 2009). Protokol ile uygulanacak önlemler şunlardır:

- Atmosfere yayılan sera gazı miktarı \% $\%$ 'i aşmamalıdır.

- Sanayi, ısıtma ve taşımacılıktan dolayı ortaya çıkan sera gazlarını azaltmaya yönelik mevzuatlar yeniden düzenlenmelidir.

- Atmosfere yayılan karbondioksit oranının düşürülmesi için yeni alternatif enerji kaynaklarına yönelik yatırımlar yapılmalıdır.

- Fosil yakıtların yerine bio-dizel yakıtlar yaygınlaşmalıdır.

- Termik santrallerde karbon salınımını azaltacak teknolojik sistemler geliştirilmelidir.

- Karbon salınımı fazla olan ülkelerden fazla vergi alınmalıdır.

Günümüzde yaşanan küresel isınma ile birlikte ekonomik büyüme ve karbon emisyonu arasındaki ilişki çevresel etkileri nedeniyle incelenen konular arasında yerini almaktadır. Ekonomik büyüme ve karbon emisyonu arasındaki ilişkinin çevresel etkileri tersine çevrilmiş U şeklinde bir ilişki olduğunu gösteren Kuznet eğrisi ile açıklanmaktadır (Mirza ve Kanwal, 2017). Çevresel Kuznet Eğrisi (ÇKE), Kuznet (1955) tarafindan gelir eşitsizliğinin başlangıçta kişi başına gelir arttıkça arttığı ve bir dönüm noktasından sonra azalmaya başladığını açıklamaktadır. Kısaca belirtmek gerekirse gelir eşitsizliği ile kişi başına düşen gelir arasındaki tersine çevrilmiş bir Uilişkisini anlatmaktadır. 1990'larda ÇKE kavramı, kişi başına gelir ile çevresel bozulmanın aynı ters U-şekilli ilişkiyi takip ettiği yönündeki hipotez ile uygulanmıştır. Bu açıklamaya göre ÇKE, bir ülkenin kişi başına düşen geliri düşük olduğunda, çevre kirliliğinde bir artış olduğunu göstermektedir. Fakat kişi başına düşen gelir arttıkça bu durumun zamanla azalacağını ileri sürmektedir (Churchill vd. 2018). ÇKE'nin temel haliyle gösterimi Şekil 1'de yer almaktadır. 


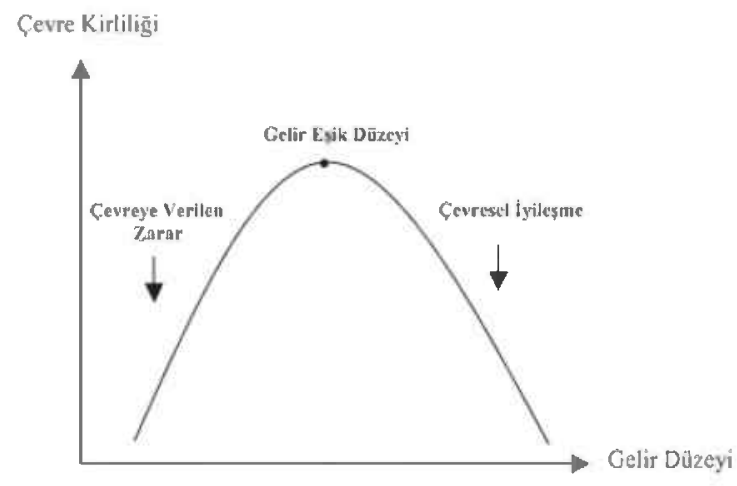

Şekil 1. Çevresel Kuznet Eğrisinin Gösterimi

Kaynak: Erataş ve Uysal, 2014.

Şekil 1'de görüldüğüü üzere, başlangıçta artan ekonomik büyüme ile birlikte çevre kirliliğinin arttığı, belirli bir tepe noktasından sonra trendin tersine döndüğü görülmektedir. Ekonomik gelişme düzeyinin artmasıyla çevre bilincinin arttı̆̆ ve çevre kirliliğinin azaldığı ileri sürülmektedir. Şekil l'de gösterilen ÇKE göre, ekonomik gelişme sürecinde çevre kirliliği önce artmakta sonra ise azalmaktadır.

Ekonomik büyüme, artan oranda elektrik kullanımı ve genel olarak enerji ile yakından ilişkilidir. Bunun yanı sıra $\mathrm{CO} 2$ emisyonlarında artışa neden olabileceği bilinmektedir (Salahuddin vd. 2015). Büyüyen ekonomilerde çoğunlukla elektrik üretimi için büyük enerji talepleri ve enerji gereksinimleri bulunmaktadır. Enerji talebindeki artışlar özellikle elektrik enerjisinin talebinin artmasına ve $\mathrm{CO} 2$ emisyonları gibi çevresel kaygılara neden olmaktadır (Salahuddin vd. 2018). İkincil enerji kaynaklarından biri olan elektrik enerjisi, birincil enerji kaynaklarının işlenmesiyle elde edilen bir tür temel enerji kaynağıdır. Elektrik enerjisi, ekonomik ve sosyal gelişmeyi teşvik etmek için kullanılan önemli bir güçtür. Artan elektrik tüketimi, özellikle endüstriyel elektrik tüketimi, bir ülkenin ekonomik kalkınma düzeyinin önemli bir sembolüdür. Elektrik üretimi ve tüketimi, ekonomik büyümenin kalitesi ve hızı üzerinde doğrudan bir etkiye sahiptir (Zhang vd. 2017). Farklı ekonomik faaliyetlere enerji sağlayan elektrik enerjisi, ekonomik büyümenin temel faktörünü temsil etmektedir. Elektrik tüketimi, çevresel kalite ve ekonomik kalkınma arasındaki nedensel bağları anlamak, enerji politikalarını verimli bir şekilde şekillendirmek için ilk adımdır (Mezghani ve Haddad, 2017).

\section{LITERATÜR İNCELEMESI}

Enerji ile ilgili yapılan ilk çalışma enerji tüketim ve büyüme ilişkisini inceleyen Kraft ve Kraft (1978)'da aittir. Bu çalışma 1947-1974 dönemlerinde Sim's tekniği kullanılarak Amerika'daki enerji tüketimi ve büyüme arasındaki nedensellik ilişkisini incelemiştir. Bu çalışmadan sonra literatürde enerji tüketimi ile ilgili farklı değişkenler kullanılarak yapılan çalışmalar hızla artmıştır. Enerji tüketimi, ekonomik büyüme, karbon emisyonu, elektrik tüketimi gibi konularda literatürde yapılmış birçok çalışma bulunmaktadır (bkz. Soytaş ve Sarı (2003), Apergis ve Payne (2009), Apergis ve Payne (2010), Sadorsky (2012), Yıldırım ve Aslan (2012), Çoban ve Topcu, (2013), Karanfil ve Li (2015), Adams vd. (2016), Ito (2017), Bakırtaş ve Akpolat (2018) gibi).

Literatürde enerji tüketimi, ekonomik büyüme ve $\mathrm{CO} 2$ emisyon ilişkisini inceleyen çalışmaların sayısı oldukça fazladır. Bu çalışmalar farklı ülkeler, zaman aralıkları ya da yöntemler kullanılarak açıklanmaya çalışılmıştır (bkz. Zhang ve Cheng (2009), Omri (2013), Salahuddin ve Gow (2014), Kasman ve Duman (2015), Begum vd. (2015), Saidi ve Hammami (2015), Chen vd. (2016), Bekhet vd. (2017) gibi). Bu çalışmaların sonuçları ekonomik anlamda çeşitli politika etkileri 
taşımaktadır. Mevcut literatürün çoğunun enerji tüketimi, ekonomik büyüme ve $\mathrm{CO} 2$ emisyon ilişkisine odaklanıldığını göstermektedir.

Tablo 1. Literatür İncelemesi

\begin{tabular}{|c|c|c|c|c|}
\hline Yazar (lar) & Yıl aralığ & Ülke/Ülke Grubu & Yöntem & Sonuc \\
\hline $\begin{array}{l}\text { Wolde-Rufael } \\
(2006),\end{array}$ & $1971-2001$ & 17 Afrika Ülkesi & $\begin{array}{l}\text { Eşbütünleşme } \\
\text { Granger Nedensellik }\end{array}$ & $\begin{array}{l}\text { Sadece } 9 \text { ülke için kişi } \\
\text { başıa düşen elektrik } \\
\text { tüketimi ile kişi } \\
\text { başina düşen reel } \\
\text { GSYIH ve Granger } \\
\text { nedensellik testine } \\
\text { göre (sadece } 12 \text { ülke } \\
\text { için) uzun süreli bir } \\
\text { ilişki olduğu sonucu } \\
\text { elde edilmiştir. }\end{array}$ \\
\hline $\begin{array}{l}\text { Narayan ve Smyth } \\
(2009)\end{array}$ & $1974-2002$ & Ortadoğu ülkeleri & Nedensellik & $\begin{array}{lr}\text { Elektrik } & \text { tüketimi, } \\
\text { ihracat ve } & \text { gayri safi } \\
\text { yurtiçi } & \text { hâsıla } \\
\text { (GSYİH) } & \text { arasındaki } \\
\text { nedensel } & \text { ilişki } \\
\text { incelenmiş, çift yönlü } \\
\text { nedensellik } & \text { olduğu } \\
\text { sonucu } & \text { elde } \\
\text { edilmiștir. } & \\
\end{array}$ \\
\hline $\begin{array}{l}\text { Ciarreta ve Zarraga } \\
(2010)\end{array}$ & $1970-2007$ & 12 Avrupa ülkesi & Panel Nedensellik & $\begin{array}{l}\text { Elektrik fiyatları ile } \\
\text { GSYİH arasinda çift } \\
\text { yönlü nedensellik } \\
\text { olduğu bulunmustur. }\end{array}$ \\
\hline Narayan vd. (2010) & $1980-2006$ & 93 ülke & Granger Nedensellik & $\begin{array}{l}\text { Uzun dönemde } \\
\text { elektrik tüketimi ve } \\
\text { reel GSYIH arasinda } \\
\text { (sadece Ortadoğu } \\
\text { ülkeleri hariç) çift } \\
\text { yönlü bir nedensellik } \\
\text { ilişkisi bulunmuştur. }\end{array}$ \\
\hline $\begin{array}{l}\text { Acaravc1 ve Öztürk } \\
(2010)\end{array}$ & $1990-2006$ & $\begin{array}{l}\text { Arnavutluk, Beyaz } \\
\text { Rusya, Bulgaristan, } \\
\text { Çek Cumhuriyeti, } \\
\text { Estonya, Letonya, } \\
\text { Litvanya, } \\
\text { Makedonya, } \\
\text { Moldova, Polonya, } \\
\text { Romanya, Rusya } \\
\text { Federasyonu, } \\
\text { Sirbistan) }\end{array}$ & $\begin{array}{ll}\text { Pedroni } & \text { Panel } \\
\text { Eşbütünleşme } & \end{array}$ & $\begin{array}{l}\text { Uzun vadede elektrik } \\
\text { tüketiminin büyüme } \\
\text { üzerinde herhangi bir } \\
\text { etkisinin olmadığ } 1 \\
\text { sonucuna ulaşlmıştır. }\end{array}$ \\
\hline $\begin{array}{l}\text { Lean ve Smyth } \\
(2010)\end{array}$ & $1980-2006$ & 5 ASEAN ülkesi & $\begin{array}{l}\text { Panel Vektör Hata } \\
\text { Düzeltme Modeli } \\
\text { Granger Nedensellik }\end{array}$ & $\begin{array}{l}\text { Uzun vadeli } \\
\text { tahminlere göre, } \\
\text { elektrik tüketimi ile } \\
\text { emisyonlar arasında } \\
\text { anlamlı bir ilişki } \\
\text { olduğu, emisyonlar ve } \\
\text { reel ç1ktı arasında } \\
\text { doğrusal olmayan bir } \\
\text { ilişki olduğu } \\
\text { gösterilmiştir. } \\
\text { Granger nedensellik } \\
\text { testine göre elektrik } \\
\text { tüketimi } \\
\text { emisyonlardan ve } \\
\text { ekonomik büyümeye } \\
\text { doğru tek yönlü } \\
\text { nedensellik } \\
\text { bulunmuștur. }\end{array}$ \\
\hline
\end{tabular}




\begin{tabular}{|c|c|c|c|c|}
\hline Bella vd. (2014) & $1965-2006$ & 22 OECD ülkesi & $\begin{array}{l}\text { Panel Vektör Hata } \\
\text { Düzeltme Modeli }\end{array}$ & $\begin{array}{lr}\text { CO2 } & \text { emisyonlan, } \\
\text { elektrik } & \text { enerjisi } \\
\text { tüketimi } & \text { ve GSYIH } \\
\text { arasında } & \text { doğrusal } \\
\text { olmayan } & \text { ilişki } \\
\text { bulunmuş } & \text { ve bu } \\
\text { ilişkilerin } & \text { birimler } \\
\text { arasında heterojen } & \text { hür. } \\
\text { olduğu görülmüstür. }\end{array}$ \\
\hline Cowan vd. (2014) & $1990-2010$ & BRICS ülkeleri & Granger Nedensellik & $\begin{array}{l}\text { BRICS ülkeleri için } \\
\text { farklı sonuçlar elde } \\
\text { edilmiştir. Bu nedenle } \\
\text { politikaların, } \\
\text { incelenmekte olan } \\
\text { BRICS ülkelerinin } \\
\text { her birinde farklı } \\
\text { etkileri olacağı ve eşit } \\
\text { şekilde } \\
\text { uygulanamayacağı } \\
\text { ifade edilmiștir. }\end{array}$ \\
\hline $\begin{array}{l}\text { Balsalobre-Lorente } \\
\text { vd. (2018) }\end{array}$ & $1985-2016$ & $\begin{array}{l}\text { Almanya, Fransa, } \\
\text { İtalya, İspanya ve } \\
\text { Birleşik Krallık }\end{array}$ & $\begin{array}{l}\text { Panel En Küçük } \\
\text { Kareler Modeli }\end{array}$ & $\begin{array}{l}\text { Yenilenebilir elektrik } \\
\text { tüketimi, } \\
\text { kaynaklar ve enerji } \\
\text { inovasyonu çevre } \\
\text { kalitesini artırırken, } \\
\text { ticari açıklı ve } \\
\text { ekonomik büyüme ile } \\
\text { yenilenebilir elektrik } \\
\text { tüketimi arasındaki } \\
\text { etkileşim, CO2 } \\
\text { emisyonlan üzerinde } \\
\text { olumlu bir etki } \\
\text { yaratmaktadır. }\end{array}$ \\
\hline $\begin{array}{l}\text { Salahuddin vd. } \\
(2018)\end{array}$ & $1980-2013$ & Kuveyt & $\begin{array}{l}\text { Otoregresif } \\
\text { Dağıtılmış Gecikme } \\
\text { (ARDL) Sınır Testi } \\
\text { VECM Granger } \\
\text { nedensellik testi }\end{array}$ & $\begin{array}{l}\text { Ekonomik } \\
\text { büyümenin, elektrik } \\
\text { tüketiminin } \\
\text { doğrudan yabancı } \\
\text { yatırımlanı hem kısa } \\
\text { hem de uzun vadede } \\
\text { CO2 emisyonların } \\
\text { teşvik ettiği sonucu } \\
\text { elde edilmiştir. }\end{array}$ \\
\hline
\end{tabular}

\section{III.VERİ SETİ, METODOLOJİ VE ÇIKARIMLAR}

1995-2014 dönemi için 2014 yılı CO2 emisyonu (kişi başına metrik ton) dünya ortalamasının $(4,9715)$ üzerinde olan 44 ülke için analiz yapılmıştır. Analizde karbon emisyonu (LCO2), elektrik tüketimi (LEC) ve ekonomik büyüme (LGDP) değişkenleri kullanılmıştır. Çalışmada kullanılan değişkenlerin tamamı Dünya Bankası Veritabanından alınarak analizde logaritmik değerler şeklinde kullanılmıştır. Çalışmanın amacı elektrik tüketimi ve ekonomik büyümenin $\mathrm{C} 02$ emisyonlan üzerindeki etkisini incelemektir. Çalışmada Panel VAR yöntemiyle verilerin elde edilebilirliğinden dolayı 1995-2014 yıl aralığı kullanılarak seçilen 44 ülke için analiz yapılmıştır. Bu dönem aralığı için veri setine ulaşılıp analize dâhil edilen ülkeler Almanya, Avusturya, Avustralya, Bahreyn, Belçika, Belarus, Birleşik Krallık, Amerika Birleşik Devletleri, Bosna Hersek, Brunei Sultanlığı, Bulgaristan, Çin, Çek Cumhuriyeti, Danimarka, Estonya, Finlandiya, Güney Afrika, Kanada, Kıbrıs, Hollanda, Hong Kong SAR, İzlanda, İran İslam Cumhuriyeti, İrlanda, İsrail, İspanya, İtalya, Japonya, Kazakistan, Kore Cumhuriyeti, Kuveyt, Lüksemburg, Malezya, Malta, Moğolistan, Norveç, Polonya, Rusya Federasyonu, Suudi Arabistan, Singapur, Trinidad ve Tobago, Ukrayna, Umman ve Yunanistan'dır. Şekil 2'de seçilen ülkelerin karbon emisyon oranlan ile Dünya Karbon Emisyon ortalaması 2014 yılı verileri baz alınarak gösterilmektedir. 


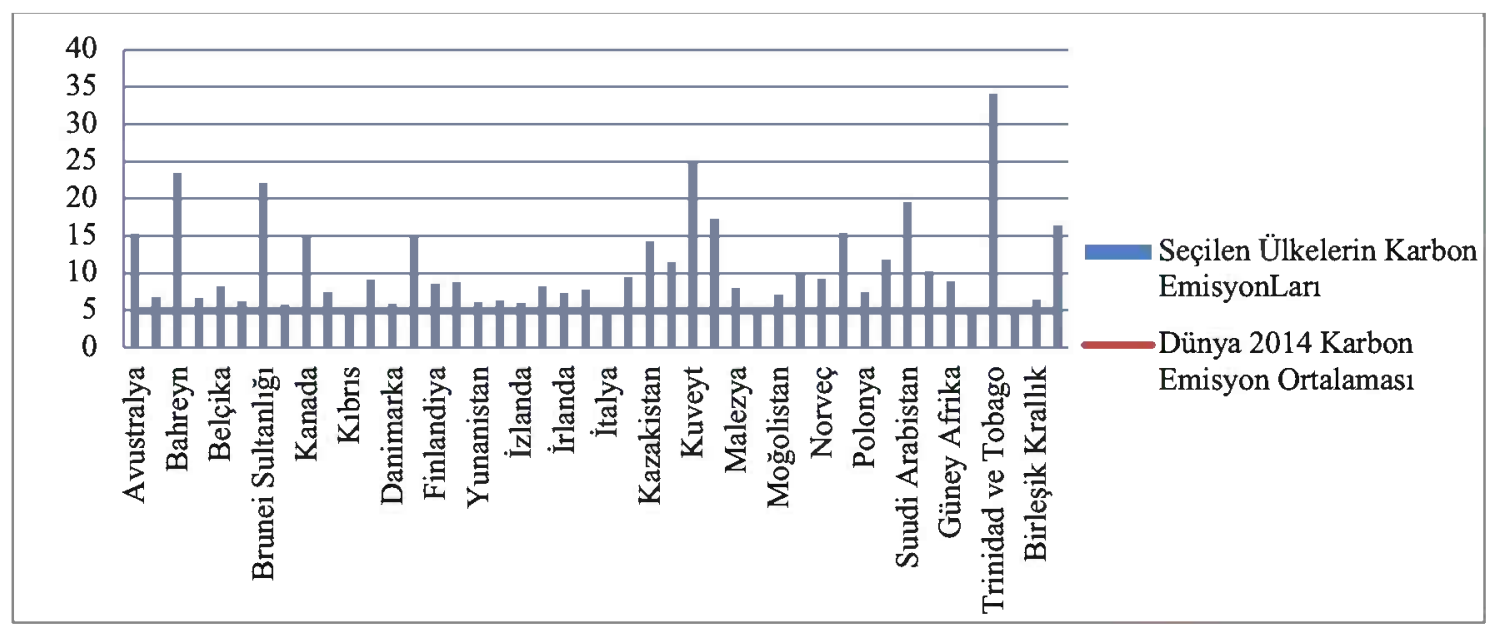

Şekil 2. Ülkelerin Karbon Emisyon Oranlarının Gösterimi

Kaynak: Dünya Bankası Veritabanı, 2018.

İlk olarak çalışmada verilerin durağanlık analizi için panel veri literatüründe sıkça kullanılan Levin, Lin ve Chu (2002) (LLC) birim kök testi kullanılmıştır. Bu test sıfır hipotezde birim kök olduğunu, alternatif hipotezde ise birim kök olmadığını ifade etmektedir. Heterojenliğe izin vermeyen LLC birim kök testi modeli şu şekildedir (Levin vd., 2002):

$$
\Delta y_{i t}=\rho_{i} y_{i, t-1}+\sum_{L=1}^{\rho_{i}} \theta_{i, L} \Delta y_{i t-L}+\alpha m_{i} d_{m t}+\varepsilon_{i t}
$$

Tablo 1'de LLC birim kök testi sonuçlarından görüldüğü üzere değişkenlerin sabit ve trendli olarak durağan hale geldiği gösterilmektedir.

Tablo 2. LLC Birim kök testi Sonuçları

\begin{tabular}{|l|l|l|}
\hline Değişkenler & Sabit & Sabit ve Trendli \\
\hline $\boldsymbol{L C O 2}$ & -0.2559 & -2.5876 \\
& 0.3990 & $0.0048^{*}$ \\
\hline $\boldsymbol{L G D P}$ & -4.3179 & -3.2108 \\
& $0.0000^{*}$ & $0.0007^{*}$ \\
\hline $\boldsymbol{L E C}$ & -3.3132 & -2.5158 \\
& $0.0005^{*}$ & $0.0059^{*}$ \\
\hline
\end{tabular}

Not: ${ }^{*},{ }^{* *},{ }^{* * *}$ sırasıyla $\% 1, \% 5$ ve $\% 10$ istatistiksel olarak anlamlılık seviyelerini göstermektedir. Analiz Stata programı kullanılarak yapılmıştır.

Serilerin durağanlıkları incelendikten sonra gecikme uzunluğu BIC, AIC ve QIC kriterleri kullanılarak belirlenmiştir. Tablo 3'de gösterilen test istatistiklerinden maksimum gecikme uzunluğu belirlenmiştir.

Tablo 3. Gecikme uzunluğunun belirlenmesi

\begin{tabular}{|l|l|l|l|l|l|l|}
\hline lag & CD & J & J pvalue & MBIC & MAIC & MQIC \\
\hline 1 & 0.9999997 & 61.65042 & 0.0001596 & -113.6401 & 7.650424 & -39.36239 \\
\hline 2 & 0.9999997 & 29.2724 & 0.0451499 & -87.58792 & -6.727602 & -38.06947 \\
\hline 3 & 0.9999997 & 20.85406 & 0.0133144 & -37.5761 & 2.854061 & -12.81688 \\
\hline
\end{tabular}


Çalışmada Geleneksel VAR tekniğinin panel veri setine uygulanmış şekli olan "Panel VAR" yöntemiyle analiz yapılmıștır. Panel VAR modeli ilk olarak Holtz-Eakin (1988) tarafindan Sims (1980) zaman serisi modellerine dayandırılarak önerilmiştir. Bu yöntemde tüm değişkenler dinamik ve statik olarak içsel olduğu kabul edilmektedir. Ancak bazı durumlarda dışsal değişkenler de analizde kullanılabilmektedir (Canova ve Ciccarelli, 2013). Ayrica bu modelin yaygın olarak kullanılmasındaki neden kesitsel dinamik heterojenliği de dikkate alarak heterojenlik kaynaklarını daha iyi anlaşılmasını sağlamasıdır (Ouyang ve Li, 2018). Geleneksel VAR modeline göre uyarlanmış Panel VAR modeli:

$$
L C O 2_{i, t}=\beta_{i}+\gamma_{i, t-j} L C O 2_{i, t-j}+\delta_{i, t-j} L G D P_{i, t-j}+\theta_{i, t-j} L E C_{i, t-j}+\mu_{i}+\varepsilon_{i, t}
$$

Burada $L C O 2_{i, t}$ bağımlı değişkeni göstermektedir. 2 no'lu denklemde her bir değişkeninin bağımlı değişken üzerindeki etkisi analiz edilmeye çalışılmaktadır. Elde edilen sonuçlar bağımlı değişkenin belirleyicilerini ortaya koymaktadır. Tablo 4'te Panel VAR analiz sonuçlan gösterilmektedir.

Tablo 4. Panel VAR test sonuçları

\begin{tabular}{|l|l|l|}
\cline { 2 - 3 } \multicolumn{1}{c|}{} & \multicolumn{2}{c|}{ Bağımlı Değişken } \\
\hline Bağımsız Değişkenler & Katsayı & \multicolumn{2}{c|}{ Olasılık değeri (p) } \\
\hline & \multicolumn{2}{c|}{ LCO2 } \\
\hline $\boldsymbol{L} \boldsymbol{G D P}$ & -0.0276687 & 0.686 \\
\hline $\boldsymbol{L E C}$ & -0.1630737 & $0.084^{* * *}$ \\
\hline
\end{tabular}

Not: *,**, *** sırasıyla \% 1, \% 5 ve \% 10 istatistiksel olarak anlamlılık seviyelerini göstermektedir. Analiz Stata programı ile yapılmı̧̧ ve maksimum gecikme uzunluğu 3 olarak belirlenmiştir.

Panel VAR analizinden elde edilen sonuçlar değişkenler arasındaki pozitif-negatif ve anlamlıanlamsız olması hakkında bilgi vermektedir. Sonuçlara göre Tablo 4'te, $\mathrm{CO} 2$ emisyonu ile ekonomik büyüme arasında negatif ve anlamsız, $\mathrm{CO} 2$ emisyonu ile elektirik tüketimi arasında negatif ve anlamlı bir ilişki olduğu görülmektedir. Buna göre $\mathrm{CO} 2$ emisyonunda yaşanacak bir birimlik artı̧ elektirik tüketiminde $0.16^{\prime}$ lık bir azalışa neden olacaktır.

Ayrıca çalışmada nedensellik analizi için Granger nedensellik-Wald testi yapılmıştır. Bu test eşitliğin sağ tarafındaki değişkenlerin $\mathrm{CO} 2$ emisyonuna neden olup olmadığını sınamak için yapılmakta ve her bir değişkenin karbon emisyonu ile nedensellik ilişkisi incelenmektedir.

Tablo 5. Granger nedensellik-Wald test sonuçları

\begin{tabular}{|l|l|l|}
\hline Değişkenler & Katsayı & Olasilık değeri \\
\hline \multicolumn{3}{|c|}{ LCO2 } \\
\hline LGDP & 0.434 & 0.510 \\
\hline LEC & 0.022 & 0.883 \\
\hline \multicolumn{3}{|l|}{ LGDP } \\
\hline LCO2 & $1.152 \quad$ LEC & 0.283 \\
\hline LEC & 0.078 & 0.780 \\
\hline \multicolumn{4}{|l|}{} \\
\hline LCO2 & $8.693 \quad 0.003^{*}$ \\
\hline LGDP & 1.745 & 0.186 \\
\hline
\end{tabular}

Not: *, **,*** sırasıyla $\% 1, \% 5$ ve $\% 10$ istatistiksel olarak anlamlılık seviyelerini göstermektedir. 
Nedensellik testi sonuçlarına göre $\% 1$ anlamlılık düzeyinde elektirik tüketiminden karbon emisyonuna doğru tek yönlü nedensellik ilişkisi bulunmaktadır. Buna göre elektrik tüketiminde yaşanacak gelişmeler $\mathrm{CO} 2$ emisyonlanı üzerinde etkili olacaktır. Ele alınan ülkelerde emisyonlanı düşürmeye yönelik olan, ekonomik büyümelerini olumsuz etkilemeyecek şekilde yapılacak yatırımları desteklemelidir.

Değişkenler arasındaki nedensellik incelemesinden sonra değişkenler arasındaki dinamik ilişkiler etki-tepki fonksiyonları ile incelenmektedir. Bu kapsamda Şekil 3 'te değişkenlerin etki-tepki fonksiyonlarından elde edilen şekiller gösterilmektedir.

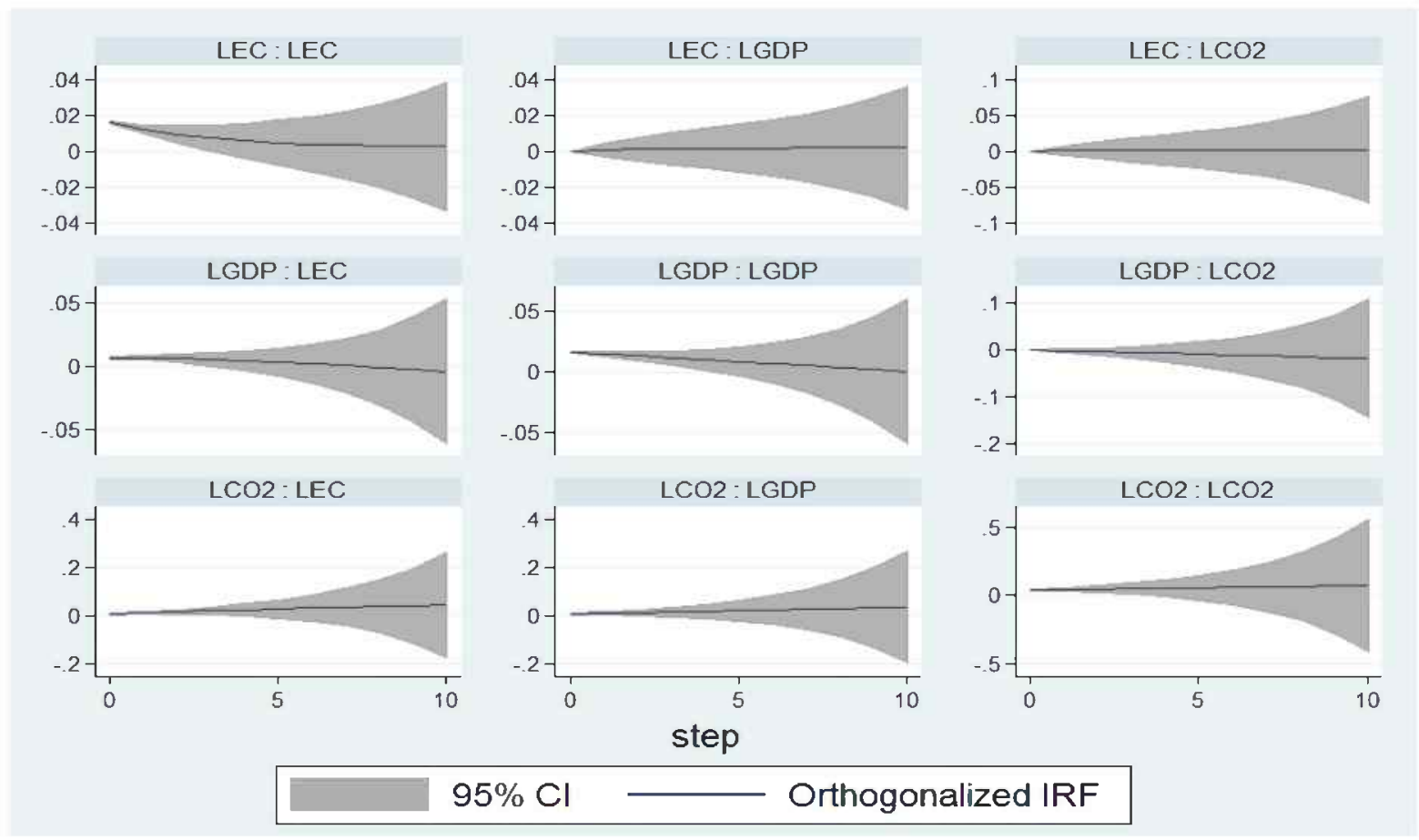

Şekil 3. Etki-Tepki Fonksiyonlanı

Panel VAR analizinin sağliklı yorumlanması için yapılan etki-tepki fonksiyonu değişkenler üzerinde yaşanacak hareketlerin etkilerini göstermektedir. Değişkenlerde ortaya çıkan standart sapmalı bir şok sadece bir değişkende meydana gelebilir ya da bir değişkende yaşanan şok başka bir değişkende ortaya çıkan bir şoka eşlik edebilir. Aynıca standart sapmalı şokun içsel değişkende şimdiki ve gelecekteki değerine olan etkisini incelemek için yapılmaktadır. Bu açıklamalara göre Şekil 3'te elektrik tüketiminde ve büyümede yaşanacak standart sapmalı bir şokun karbon emisyonunu sabit bir şekilde etkilediği görülmektedir.

\section{SONUÇ}

Çalı̧̧ma 1995-2014 dönemlerinde elektrik tüketimi, karbon emisyonu ve ekonomik büyüme arasındaki ilişkiyi incelemek amacıyla yapılmıştır. Elektrik tüketimi ve ekonomik büyüme değişkenlerinin seçilmiş ülkelerde $\mathrm{CO} 2$ emisyonuna yol açıp açmadığını ilişkinin incelenmesi için karbon emisyonu dünya ortalamasının üzerinde olan verilerine ulaşılabilen 44 ülke verileri kullanılmıştır. Çalışmada öncelikle LLC birim kök testi kullanılarak serilerin durağan olup olmadıkları test edilmiştir. LLC birim kök testinde serilerin sabit ve trendli olarak durağan oldukları görülmüştür. Daha sonra değişkenler kullanılarak Panel VAR tekniğiyle analiz yapılmıştır. Bu analizden elde edilen sonuçlara göre $\mathrm{CO} 2$ emisyonu ile ekonomik büyüme arasında negatif ve 
anlamsız, $\mathrm{CO} 2$ emisyonu ile elektirik tüketimi arasında negatif ve anlamlı bir ilişki olduğu sonucu elde edilmiştir. Buna göre $\mathrm{CO} 2$ emisyonunda yaşanacak bir birimlik artış elektirik tüketimi üzerinde $0.16^{\prime}$ 'lk bir azalışa neden olacağ 1 yönünde yorum yapılabilmektedir. Yapılan nedensellik testi sonuçlarına göre elektrik tüketiminde yaşanacak gelişmelerin $\mathrm{CO} 2$ emisyonları üzerinde etkili olacağı yani elektirik tüketiminden $\mathrm{CO} 2$ emisyonuna doğru tek yönlü nedensellik ilişkisi bulunmuştur. Elektrik tüketiminin $\mathrm{CO} 2$ emisyonuna yol açması, ülkelerin emisyon değerlerini azaltacak ve elektirik enerjisi verimliliğini artıracak yatırımlan desteklemesini gerektirmektedir. Ayrıca analizde kullanılan ülkeler rüzgâr, güneş gibi yenilenebilir enerji kaynaklarını kullanarak elektrik enerjisi üretebilirler. Bu nedenle hükümetler yenilenebilir enerji kaynaklarının kullanımına teşvik etmek amacıyla yatırımlar yapmalıdırlar. Nüfus artışı ve hızlı kentleşme ile birlikte ulaşım ve taşımacılık sektörünün de gelişmesi emisyon oranlarında artışa neden olabilir. Ülkeler bu sektörlerden kaynaklanabilecek emisyonların azaltılmasına dikkat etmelidir. Alınacak önlemlerle yeni teknolojik gelişmelere teşvik edilmesi, yenilenebilir enerji kaynaklanından enerji elde edilmesi için yatırımlar yapılmasına, bu kaynakların geliştirilmesi üzerine araştırma ve geliştirmeye yönelik çalışmalar yapılmasına, enerjinin hane halkları tarafından verimli kullanılmasına ve CO2 emisyonlarının çevresel etkilerinin azaltılmasını sağlayacaktır.

Bu çalışmanın sınırlarından bir tanesi analizin tüm ülkeleri kapsayan bir düzeyde yapılmasıdır. Belirlenen ülkelerin ortak özellikleri $\mathrm{CO} 2$ emisyonu dünya ortalamasının üzerinde olan ülkeler olması, elektrik enerjisini elde etmek için termik santraller kullanmalanı ve fosil yakıt üretimi yapmalarıdır. Ülkelerin farklı elektrik tüketimine sahip olmasından dolayı bundan sonra yapılacak çalışmalar bu ülkeleri tek olarak ele alarak, farklı analiz yöntemleri kullanarak çevresel bozulmalar hakkında daha fazla bilgi sahibi olabilirler.

\section{KAYNAKÇA}

Acaravc1, A., \& Öztürk, İ. (2010). Electricity consumption-growth nexus: Evidence from panel data for transition countries. Energy Economics , 32 (3), 604-608.

Adams, S., Klabodu, E. K., \& Opoku, E. E. (2016). Energy consumption, political regime and economic growth in Sub-Saharan Africa. Energy Policy, 36-44.

Apergis, N., \& Payne, J. E. (2009). Energy consumption and aconomic growth: evidence from the commonwealth of Independent States. Energy Economics , 641-647.

Apergis, N., \& Payne, J. E. (2010). Renewable energy consumption and economic growth: evidence from a panel of OECD countries. Enegy Policy, 656-666.

Bakırtaş, T., \& Akpolat, A. G. (2018). The relationship between energy consumption, urbanization, and economic growth in new emerging-market countries. Energy, 110-121.

Balsalobre-Lorente, D., Shahbaz, M., Roubaud, D., \& Farhani, S. (2018). How economic growth, renewable electricity and natural resources contribute to $\mathrm{CO} 2$ emissions? Energy Policy, 113, 356-367.

Begum, R. A., Sohag, K., Abdullah, S. M., \& Jaafar, M. (2015). CO2 emissions, energy consumption, economic and population growth in Malaysia. Renewable and Sustainable Energy Reviews , 41, 594-601.

Bekhet, H. A., Matar, A., \& Yasmin, T. (2017). CO2 emissions, energy consumption, economic growth, and financial development in GCC countries: Dynamic simultaneous equation models. Renewable and Sustainable Energy Reviews , 70, 117-132.

Bella, G., Massidda, C., \& Mattana, P. (2014). The relationship among CO2 emissions, electricity power consumption and GDP in OECD countries. Journal of Policy Modeling , 36 (6), 970-985. 
Canova, F., \& Ciccarelli, M. (2013). Panel VectorAutoregressive Models A Survey. European Central Bank, (Working Paper).

Chen, P.-Y., Chen, S.-T., Hsu, C.-S., \& Chen, C.-C. (2016). Modeling the global relationships among economic growth, energy consumption and $\mathrm{CO} 2$ emissions. Renewable and Sustainable Energy Reviews , 65, 420-431.

Churchill, S. A., Inekwe, J., Ivanovski, K., \& Smyth, R. (2018). The Environmental Kuznets Curve in the OECD: 1870-2014. Energy Economics (75), 389-399.

Ciarreta, A., \& Zarraga, A. (2010). Economic growth-electricity consumption causality in 12 European countries: A dynamic panel data approach . Energy Policy, 3790-3796.

Cowan, W. N., Chang, T., Inglesi-Lotz, R., \& Gupta, R. (2014). The nexus of electricity consumption, economic growth and $\mathrm{CO} 2$ emissions in the BRICS countries. Energy Policy, 66, 359368.

Çoban, S., \& Topcu, M. (2013). The nexus between financial development and energy consumption in the EU: A dynamic panel data analysis. Energy Economics , 81-88.

Dünya Bankası Veritabanı, (Erişim Tarihi: 09.10.2018)

Erataş, F., \& Uysal, D. (2014). Çevresel Kuznets Eğrisi Yaklaşımının "BRICT" Ülkeleri Kapsamında Değerlendirilmesi. İktisat Fakültesi Mecmuası , 64, 1-25.

Ito, K. (2017). CO2 emissions, renewable and non-renewable energy consumption and economic growth: evidence from panel data for develpoing countries. International Economics , 16.

Karanfil, F., \& Li, Y. (2015). Electricity consumption and economic growth: exploring panelspecific differences. Energy Policy, 264-277.

Kasman, A., \& Duman, Y. S. (2015). CO2 emissions, economic growth, energy consumption, trade and urbanization in new EU member and candidate countries: A panel data analysis. Economic Modelling , 44, 97-103.

Lean, H. H., \& Smyth, R. (2010). CO2 emissions, electricity consumption and output in ASEAN. Applied Energy , 87 (6), 1858-1864.

Lorente, D. B., Shahbaz, M., Roubaud, D., \& Farhani, S. (2018). How economic growth, renewable electricity and natural resources contribute to $\mathrm{CO} 2$ emissions?. Energy Policy (113), 356367.

Mezghani, I., \& Haddad, H. B. (2017). Energy consumption and economic growth: An empirical study of the electricity consumption in Saudi Arabia. Renewable and Sustainable Energy Reviews (75), 145-156.

Mirza, F. M., \& Kanwal, A. (2017). Energy consumption, carbon emissions and economic growth in Pakistan: Dynamic causality analysis. Renewable and Sustainable Energy Reviews (72), 1233-1240.

Narayan, P. K., \& Smyth, R. (2009). Multivariate Granger causality between electricity consumption, export and GDP: evidence from a panel of Middle Eastern countries. Energy Policy, 229-236.

Narayan, P. K., Narayan, S., \& Popp, S. (2010). Does electricity consumption panel Granger cause GDP? A new global evidence. Applied Energy, 3294-3298.

Omri, A. (2013). Our objective, in this study, is to investigate the impact of economic growth and $\mathrm{CO} 2$ emissions on energy consumption for a panel of 58 countries during 1990-2012. For this reason, we used, as an investigate technique, a dynamic panel data model, which fo. Energy Economics , 40, 657-664. 
Ouyang, Y., \& Li, P. (2018). On the nexus of financial development, economic growth, and energy consumption in China: New perspective from a GMM panel VAR approach. Energy Economics , 238-252.

Özmen, T. M. (2009). Sera Gazı - Küresel Isınma ve Kyoto Protokolü. TMMOB İnşaat Mühendisleri Odast Yayını, 453-2009/1, 42-46.

Payne, J. E. (2010). A survey of the electricity consumption-growth literature. Applied Energy $, 87(3), 723-731$.

Sadorsky, P. (2012). Energy consumption, output and trade in South America. Energy Economics , 476-488.

Saidi, K., \& Hammami, S. (2015). The impact of CO2 emissions and economic growth on energy consumption in 58 countries. Energy Reports , 1, 62-70.

Salahuddin, M., \& Gow, J. (2014). Economic growth, energy consumption and CO2 emissions in Gulf Cooperation Council countries. Energy, 73, 44-58.

Salahuddin, M., Alam, K., Öztürk, İ., \& Sohag, K. (2018). The effects of electricity consumption, economic growth, financial development and foreign direct investment on $\mathrm{CO} 2$ emissions in Kuwait. 81 (2), 2002-2010.

Salahuddin, M., Gow, J., \& Ozturk, İ. (2015). Is the long-run relationship between economic growth, electricity consumption, carbon dioxide emissions and financial development in Gulf Cooperation Council Countries robust? Renewable and Sustainable Energy Reviews (51), 317-326.

Soytaş, U., \& Sarı, R. (2003). Energy consumption and GDP: causality relationship in G-7 countries and emerging marketing. Energy Economics, 33-37.

Wolde-Rufael, Y. (2006). Electricity consumption and economic growth: a time series experience for 17 African countries. Energy Policy, 34 (10), 1106-1114.

Y1ldirm, E., \& Aslan, A. (2012). Energy consumption and economic growth nexus for 17 highly developed OECD countries: further evidence based on bootstrap-corrected causality test. Energy Policy, 985-993.

Zhang, C., Zhou, K., Yang, S., \& Shao, Z. (2017). On electricity consumption and economic growth in China. Renewable and Sustainable Energy Reviews (76), 353-368.

Zhang, X. P., \& Cheng, X. M. (2009). Energy consumption, carbon emissions, and economic growth in China. Ecological Economics , 68 (10), 2706-2712. 